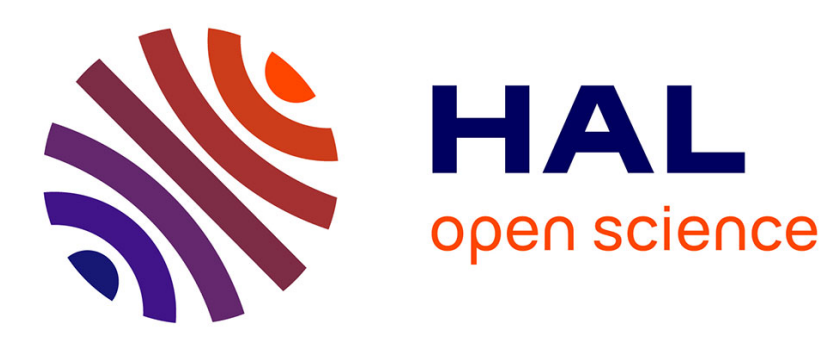

\title{
La gauche littéraire polonaise devant la guerre: entre catastrophisme et engagement antifasciste
}

\author{
Stanislaw Fiszer
}

\section{To cite this version:}

Stanislaw Fiszer. La gauche littéraire polonaise devant la guerre: entre catastrophisme et engagement antifasciste. Aden, Paul Nizan et les années 30. Revue du G.I.E.N., 2021, 17, pp.31-44. 10.3917/aden.017.0031. hal-03150614

\section{HAL Id: hal-03150614 \\ https://hal.science/hal-03150614}

Submitted on 23 Feb 2021

HAL is a multi-disciplinary open access archive for the deposit and dissemination of scientific research documents, whether they are published or not. The documents may come from teaching and research institutions in France or abroad, or from public or private research centers.
L'archive ouverte pluridisciplinaire HAL, est destinée au dépôt et à la diffusion de documents scientifiques de niveau recherche, publiés ou non, émanant des établissements d'enseignement et de recherche français ou étrangers, des laboratoires publics ou privés. 


\title{
La gauche littéraire polonaise devant la guerre : entre catastrophisme et engagement antifasciste
}

\author{
Stanisław Fiszer \\ Université de Lorraine
}

Les séquelles de la Première Guerre mondiale n'avaient pas encore été éliminées, que déjà le spectre d'une nouvelle guerre hantait la société polonaise, en particulier ses élites intellectuelles. Quasiment dès l'arrivée d'Hitler au pouvoir, la gauche littéraire s'était engagée dans une lutte antifasciste. Cependant, elle était divisée et très hétérogène.

$\mathrm{Au}$ sein de cette gauche littéraire, on peut grosso modo distinguer dans les années Trente trois courants principaux. Le premier, le plus radical, représente l'idéologie révolutionnaire, proche du marxisme et du Parti communiste de Pologne (KPP). Le deuxième, le plus hétéroclite, mais aussi le plus influent, se compose des écrivains progressistes qui se regroupent autour des très libérales Wiadomości Literackie [Nouvelles littéraires] et de son rédacteur en chef, Mieczysław Grydzewski. Enfin, les poètes de la seconde avant-garde, qualifiés de « catastrophistes », sympathisent avec la pensée socialiste au sens large du terme.

Pour comprendre l'attitude de ces gauches littéraires devant l'imminence de la guerre, il faut tout d'abord esquisser leur évolution avant l'année fatidique 1938-1939 en citant les représentants les plus marquants de chaque courant.

\section{Écrivains révolutionnaires et libéraux de gauche}

Les écrivains révolutionnaires, en majorité partisans de la Révolution russe, ont adhéré à l'internationalisme du Komintern. Pourtant, seuls quelques-uns sont militants clandestins du Parti communiste ${ }^{1}$ délégalisé en 1919 pour son soutien à 1'Armée rouge lors de la guerre soviéto-polonaise (1919-1921). Suite au premier Congrès international des écrivains pour la défense de la culture, qui s'est tenu à Paris en juin 1935, les communistes ont pris l'initiative d'organiser un Congrès des travailleurs de la culture. Parmi ses organisateurs figure Maxim Gorki, dont le portrait orne par ailleurs une salle de conférences, mais lui-même n'y a pas participé. Le congrès a eu lieu en mai 1936 à Lwów et a coïncidé avec un mouvement de grèves et la constitution d'un Front populaire dans le pays. En raison de son caractère

\footnotetext{
${ }^{1}$ Parmi les adhérents du Parti communiste, on peut mentionner Stanisław Ryszard Stande (1891-1934) et Witold Wandurski (1891-1934), tous les deux arrêtés en Union soviétique et condamnés à mort par le régime stalinien.
} 
résolument antifasciste, il a mobilisé non seulement les écrivains révolutionnaires, mais encore une frange d'intellectuels, d'hommes de lettres et d'artistes de gauche ${ }^{2}$. Tous s'opposent à la montée des fascismes en Europe et des tendances fascisantes en Pologne au sein du régime de sanacja $^{3}$, de plus en plus proche de l'endecja (le Parti national-démocrate) ${ }^{4}$, ultranationaliste et antisémite ${ }^{5}$. Les participants au congrès ont appelé à la défense de la culture et de l'humanisme, tout en dénonçant une politique de discrimination à l'égard des minorités (31\% de la société polonaise de l'époque), en particulier ukrainienne, juive et biélorusse.

Un autre événement qui a rapproché les écrivains révolutionnaires dans leur lutte antifasciste a été la guerre d'Espagne (1936-1939). Nombre de poèmes témoignent de leur élan de solidarité avec les républicains et les brigades internationales. Jan Wyka (1902-1992), lui-même combattant aux côtés des républicains, compose sur les champs de batailles une «Hiszpańska Warszawianka » [Varsovienne espagnole] ${ }^{6}$ à la gloire de la XIII brigade de Jarosław Dąbrowski ${ }^{7}$ et des volontaires polonais. Déchus, en 1939, de leur nationalité par la

\footnotetext{
${ }^{2}$ Parmi les participants au congrès il y a les écrivains Władysław Broniewski, Marian Czuchnowski, Leon Kruczkowski, Wincenty Rzymowski, Emil Zegadłowicz, le peintre Andrzej Pronaszko, l'acteur et metteur en scène Bronisław Dąbrowski, le philosophe Tadeusz Kotarbiński, le sociologue Stefan Czarnowski. Pour éviter des tensions et une éventuelle scission au sein des délégués, comme celle qui s'est produite lors du congrès à Paris entre les surréalistes et le parti communiste, les organisateurs n'ont pas invité certains écrivains d'avantgarde, pourtant très proches des idées révolutionnaires, tels que Julian Przyboś ou Tadeusz Peiper. Il n'empêche que la présence de quelques trotskistes a soulevé des objections lors du congrès.

${ }^{3}$ Le régime de sanacja [d'assainissement] avait été instauré par le maréchal Józef Piłsudski après son coup d'État de mai 1926 soutenu par la gauche polonaise (y compris les communistes) opposée à la droite alors au pouvoir. Le régime de sanacja se durcit dans les années trente. En 1930, à la veille des élections législatives, Piłsudski avait emprisonné et fait juger à Brześć les chefs de l'opposition parlementaire : à l'issue de ce procès certains condamnés avaient dû quitter le pays. En 1932, le régime avait créé à Bereza Kartuska le camp de prisonniers politiques. Au lendemain de la mort de Piłsudski, en 1935, il modifiera la Constitution qui renforcera les prérogatives du président au détriment du parlement. Désormais les colonels au pouvoir restreindront progressivement les libertés des partis politiques et, sous couleur de « front national », truqueront les élections.

${ }^{4}$ Roman Dmowski (1864-1939), le fondateur de l'endecja influencé par le darwinisme social, considère la nation comme une entité «naturelle», quasi biologiquement apparentée et vouée à une lutte pour survie avec d'autres « races », en particulier avec les Juifs, jugés « inassimilables ». Partant du principe « organique » et « unitaire », Dmowski exigeait une soumission inconditionnelle des intérêts privés à l'intérêt de la nation où toute diversité ethnique et culturelle doit être éliminée.

${ }^{5}$ Parmi les mesures antisémites qui ont fait tache d'huile dans certains endroits du pays, on peut citer le « getto lawkowe » [ghetto des bancs]. C'est une mesure instaurée dans des universités sous la pression des étudiants d'extrême droite appartenant à la Jeunesse pan-polonaise (Młodzież Wszechpolska) associée à l'endecja. Cette organisation exigeait que les étudiants juifs soient assis dans un coin particulier des salles de cours. Elle réclamait aussi l'«aryanisation» de la vie académique et l'adoption d'un numerus clausus, soit l'interdiction pour les Juifs de faire des études supérieures.

${ }^{6}$ Ce poème est inspiré de «Warszawianka 1831 roku» [La Varsovienne de 1831], une chanson polonaise patriotique, le symbole de l'insurrection de novembre 1830. Le texte polonais est la traduction du poème français «La Varsovienne », composé en février 1831 par le poète parisien Casimir Délavigne.

${ }^{7}$ La brigade de Jarosław Dąbrowski se composait de bataillons polonais, hongrois et franco-belge. Au total, 5000 volontaires polonais ont combattu en Espagne, dont environ 3000 ont péri.
} 
sanacja ${ }^{8}$, ils seront internés, pour la plupart, en France ${ }^{9}$. Władysław Broniewski (1897-1962), figure emblématique de la poésie révolutionnaire de l'entre-deux-guerres, fait cause commune avec le peuple espagnol dans le poème «Cześć i dynamit » [La Gloire et le dynamite], dont voici la fin: «Walka za nami. Walka przed nami./Ja chce wam rzucić za Pireneje/serce poety : cześć i dynamit! » [Le combat derrière nous. Le combat devant nous./ Je veux vous lancer de l'autre côté des Pyrénées/ le cœur d'un poète : honneur et dynamite!] ${ }^{10}$. Quant à Julian Przyboś (1901-1970), poète d'avant-garde de Cracovie, il affirme : «Madryt zwycięży na ulicach Warszawy » [Madrid triomphera dans les rues de Varsovie] ${ }^{11}$. Ainsi, les écrivains révolutionnaires continuent la tradition des luttes insurrectionnelles du $\mathrm{XIX}^{\mathrm{e}}$ siècle «pour notre liberté et la vôtre » tout en radicalisant leurs programmes et objectifs.

À la différence des révolutionnaires, les libéraux de gauche sont restés méfiants à l'égard du régime stalinien, du Komintern et de son idéologie d'un front antifasciste commun $^{12}$. Le libéralisme et les démocraties occidentales sont à leurs yeux un allié naturel dans la lutte contre les totalitarismes montants.

Les pacifistes libéraux forment un groupe à part et leurs convictions s'apparentent à celles du pacifisme européen des années trente ${ }^{13}$. Józef Wittlin (1896-1976) a choisi pour héros de son roman Sól ziemi [Sel de la terre], publié en 1936 et traduit en plusieurs langues, un paysan illettré des Carpates. Il porte le nom Niewiadomski (Inconnu) qui symbolise un soldat moyen de l'armée autrichienne pendant la Première Guerre mondiale. À l'instar d'un

\footnotetext{
${ }^{8}$ Glorifiés dans la Pologne communiste, les volontaires polonais de la guerre d'Espagne sont assimilés à des terroristes dans la Pologne d'aujourd'hui : l'Institut de la mémoire nationale - Commission de poursuite des crimes contre la nation polonaise (Instytut Pamięci Narodowej - Komisja Ścigania Zbrodni przeciwko Narodowi Polskiemu ou IPN), créé en 1998 en Pologne à des fins de « décommunisation », a qualifié la XIII brigade de Jarosław Dąbrowski d'organisation servant la «criminelle idéologie communiste » et préconisé la suppression des noms de rues commémorant les volontaires de cette brigade.

${ }^{9}$ Sur le sort des républicains espagnols internés en France, voir Denis Fernadez Reccatala, « Des camps pour les républicains espagnols », Le Monde diplomatique, février 1999 et Anne Mathieu, «En 1939, plongée dans les camps de réfugiés espagnols en France », Le Monde diplomatique, août 2019.

${ }^{10}$ Stefan Flukowski, un autre poète d'avant-garde, se solidarise avec le peuple espagnol dans un poème « $\mathrm{Na}$ upadek Madrytu » [À la chute de Madrid] composé en 1937.

11 Julian Przyboś, « Na granicy», in Antologia polskiej poezji rewolucyjnej 1918-1939, Wrocław, Zakład Narodowy imienia Ossolińskich, 1982.

${ }^{12}$ La méfiance des libéraux progressistes envers l'URSS résulte d'une comparaison des idéaux communistes avec la réalité du régime stalinien. En 1932, par exemple, Antoni Słonimski a visité l'Union soviétique et les articles qu'il a écrit sur ce voyage, parus dans Moja podróź do Rosji [Mon voyage en Russie, 1932] témoignent de son désenchantement identique à celui d'autres écrivains européens qui visitèrent ce pays, comme Bertrand Russell ou André Gide.

${ }^{13}$ On observe une renaissance du pacifisme européen dans les années trente grâce à la création, en 1934, de Peace Pledge Union en Angleterre, l'organisation pacifiste qui, dans la deuxième moitié des années trente est accusée, en partie à tort, d'avoir sympathisé avec le régime nazi. La traduction en polonais de l'ABC $d u$ mouvement pour la paix, dates et faits d'Anna Th. Nilsson, en 1937, avec l'Introduction de Zofia Nałkowska et Tadeusz Kotarbiński, témoigne de l'intérêt porté par des intellectuels du pays pour le mouvement pacifiste.
} 
héros kafkaïen, happé par un mécanisme qui le dépasse, il ne comprend pas pourquoi les hommes sont amenés à s'entre-tuer et qui décide de leur sort funeste.

Un autre écrivain, Antoni Słonimski (1895-1976), exprime des idées pacifistes dans ses Kroniki Tygodniowe [Chroniques hebdomadaires]. Pour ce rationaliste et libéral de gauche, ami de George Bernard Shaw, Herbert George Wells et Bertrand Russell, la guerre est une «fabrique de cadavres ${ }^{14}$. Dans l'un de ses poèmes, écrit dès la fin des années vingt, il parle d'un «défilé de trente mille invalides ${ }^{15}$. Paradoxalement, c'est au nom de son pacifisme que Słonimski combat le fascisme en Europe et dans son propre pays. Cependant, dans la première moitié des années trente, il considère les régimes instaurés en Italie et en Allemagne comme des phénomènes politiques dangereux, mais éphémères, et peint Hitler et Mussolini comme les bouffons d'une intelligence bornée. En 1937, dans son roman d'anticipation satirique Dwa końce świata [Deux fins du monde], inspiré sans doute de la Guerre des salamandres (1936) de Karel Čapek ${ }^{16}$, Słonimski représente un dictateur du nom de Retlich, à l'évidence une anagramme de celui d'Hitler, comme un personnage ridicule et loufoque, qui s'adresse ainsi à ses futures victimes :

À six heures précises tous les hommes [...] doivent lever leur jambe droite et crier : « Hip, hip Retlich !» Vous devez hurlez ainsi [...] jusqu'à sept heures. Alors vous crèverez. [...] Les Juifs, les pacifistes, les pasteurs et les membres de l'Armée du Salut n'ont pas le privilège de lever leur jambe... ${ }^{17}$

Malgré un ton burlesque, ce roman de Słonimski marque la fin de son optimisme pacifiste et annonce ses analyses plus approfondies du nazisme. Désormais, il regardera Hitler comme un «génie » qui savait répondre aux désirs des masses pour instrumentaliser celles-ci à ses propres fins, à l'aide des moyens de propagande modernes, en particulier la radio.

Ses Chroniques hebdomadaires sont aussi un baromètre de l'actualité politique de l'époque : leur auteur dénonce l'incendie de Reichstag en 1933, l'autodafé du 10 mai de la même année devant l'opéra de Berlin, la nuit des Longs Couteaux un an plus tard, les

\footnotetext{
${ }^{14}$ Antoni Słonimski, Kroniki tygodniowe 1927-1931, Warszawa, 2001, p. 272.

${ }^{15}$ On retrouve cette image grotesque dans le poème « Oko w oko » [Face à face, 1928].

${ }^{16}$ Stanisław Fiszer rapproche les deux romans en question dans l'article «Deux visions grotesques de la fin du monde chez Karel Čapek et Antoni Słonimski », in idem (dir.), Le Grotesque de l'Histoire, Paris, Le Manuscrit, 2005.

${ }^{17}$ Antoni Słonimski, Dwa końce świata, Warszawa, Ksiąźka i Wiedza, 1991, p. 29. On peut trouver une analyse plus détaillée du roman de Słonimski dans : Stanisław Fiszer, Le catastrophisme grotesque. La prose polonaise et l'anti-utopie européenne de l'entre-deux-guerres, Paris, Éditions Le Manuscrit, 2007. La citation traduite par nous-même.
} 
persécutions des Juifs, qui ont culminé lors de la nuit de Cristal en novembre 1938. Vu ces événements, Słonimski critique vivement un rapprochement entre la Pologne et l'Allemagne suite à la signature du Pacte de non-agression entre les deux États (1934). Il s'indigne, en particulier, contre une invitation de Josef Goebbels à Varsovie, en 1934, ou celle de H. Göring à la chasse dans la forêt de Białowieża, à laquelle le dignitaire nazi a participé à quatre reprises, entre 1933 et $1938^{18}$.

Pourtant, ce qui préoccupe le plus les écrivains libéraux progressistes, dont certains d'origine juive, est l'évolution de la situation politique dans leur propre pays. Słonimski observe avec inquiétude les progrès du Camp national-radical (ONR) ${ }^{19}$, créé en 1934 par des jeunes dissidents du Parti national-démocrate. Ceux-ci, inspirés par le fascisme italien et secondés par la presse antisémite, en particulier l'hebdomadaire littéraire Prosto z mostu [Sans ambages $]^{20}$, prêchent un «fascisme polonais ». L'aile la plus extrémiste du mouvement, la Falanga, sème la terreur parmi les Juifs, les communistes et les intellectuels de gauche. Pour Słonimski, le programme de l'ONR est un «plagiat lamentable » du nazisme. Il propose donc sarcastiquement de créer un nouvel État, Endehit, à la frontière entre la Pologne et l'Allemagne, habité par les membres de l'endecja et les hitlériens :

Dans ce pays-là - dit-il - on enseignerait aux enfants l'histoire de tous les massacres, violences et guerres. On consacrerait des cours particuliers à l'apprentissage de la technique de pogromes. Pour vérifier si les enfants soupçonnés d'avoir du sang dravidien ont du sang aryen, leurs camarades de classe devraient les battre à coups de bâton et les fouetter ${ }^{21}$.

À la fin des années Trente on observe un rapprochement de la jeunesse d'extrême droite et du régime dit des « colonels ». Ces derniers ont accédé au pouvoir après la mort du maréchal Piłsudski, en 1935. L'un d'entre eux, le colonel Koc, a mis sur pied une nouvelle organisation, le Camp de l'Unité nationale $(\mathrm{O} . \mathrm{Z} \text {. N. ou Ozon })^{22}$ visant à rassembler toute la

\footnotetext{
${ }^{18}$ Lors de ces quatre visites en Pologne, entre 1933 et 1938, Hermann Göring cherche à déterminer le maréchal Jőzef Piłsudski, le président I. Mościcki et d'autres ténors du régime de sanacja à adhérer au pacte antiKomintern, proposition rejetée par les Polonais.

${ }^{19}$ L'ONR a été réactivé en Pologne en 1993 et officiellement enregistré comme une association en 2012.

${ }^{20}$ Prosto $z$ mostu, dont le rédacteur en chef, Stanisław Piasecki (1900-1941), et ses collaborateurs propagent les idées antisémites à la fin des années Trente, est l'un des hebdomadaires littéraires de droite les plus populaires entre 1935 et 1939. Paradoxalement, il prône en même temps le sionisme car la création d'un État juif permettrait à la Pologne de « se débarrasser » de cette importante minorité.

${ }_{21}$ Antoni Słonimski, Kroniki tygodniowe 1932-1935, Warszawa, 2001, p. 62. Traduction de la citation en français par Stanisław Fiszer.

${ }^{22}$ Le nom de cette organisation ultranationaliste a été forgé par Ferdynand Goetel, l'auteur de Pod znakiem faszyzmu [Sous le signe du fascisme, 1938], ouvrage dans lequel il exprime ses sympathies pour le nazisme et le régime hitlérien.
} 
droite. Il propage régulièrement, dans ses émissions de radio, l'idée d'un Führer pour la Pologne (Wódz) et celui-ci ne pouvait être que le «surhumain» Edward Rydz-Śmigły qui avait succédé à Jőzef Piłsudski.

Proches de la sanacja dans les années vingt, les libéraux de gauche de Wiadomości Literackie s'en sont éloignés dans les années trente pour s'y opposer résolument à la fin de cette décennie. Słonimski tourne en dérision la proposition d'une femme de lettres, thuriféraire du régime, qui, à l'occasion de la visite de Galeazzo Ciano en Pologne, en 1938, préconise l'instauration d'une version polonaise du salut hitlérien ${ }^{23}$.

Cependant, la critique la plus virulente des colonels au pouvoir est exprimée dans un long et puissant poème satirique de Julian Tuwim, Bal w operze [Bal à l'opéra]. Composé en 1936, il n'est publié intégralement qu'après la guerre à cause de la censure. Dans la première partie du poème, avec la nervosité éblouissante d'un rythme endiablé des vers, l'auteur décrit d'une manière grotesque et caricaturale des généraux, des diplomates, des banquiers, des catins et des agents en civil. Toute cette société bigarrée se retrouve à un bal dans le palais d'un dictateur fasciste, Pantocrator. Les personnages, ainsi que le cadre dans lequel ils évoluent font tout de suite penser à la Varsovie des années Trente. Le vocable «IDEOLO », écrit en majuscules et répété à plusieurs reprises, est, à n'en pas douter, une allusion à l'idéologie du régime des colonels, en particulier à son mot d'ordre Silni, zwarci, gotowi [Forts, unis, prêts] ${ }^{24}$, qui masquait la réelle faiblesse de la Pologne à la veille de la guerre. Pourtant, le poème, en plus d'être satirique, a une dimension apocalyptique car l'horreur qu'éprouve Tuwim pour les soi-disant élites de la nation se mêle à un pressentiment d'une catastrophe imminente. En effet, portant à l'origine une devise tirée de l'Apocalypse selon saint Jean, le poème se termine par la fin du monde.

\section{Visions catastrophistes}

Les tendances catastrophistes, présentes déjà dans la première décennie de la Pologne indépendante chez les écrivains, tels que Stanisław Ignacy Witkiewicz $(1885-1939)^{25}$ ou

\footnotetext{
${ }^{23}$ Il s'agit de Maria Jehanne Wielopolska (1882-1940), l'auteure d'un roman subversif et anticlérical Kryjaki (1913), qui, après le coup d'État du maréchal Piłsudski, s'est consacrée, en tant que journaliste, à la glorification de la politique de la sanacja.

${ }^{24}$ En mai 1939, M. J. Wielopolska publie un ouvrage de propagande Silni, zwarci, gotowi, ale i... czujni [Forts, unis, prêts, mais aussi...vigilants] dans lequel elle attaque les poètes «pacifistes » et «antimilitaristes », entre autres Tuwim, Słonimski, Wittlin, Broniewski.

${ }^{25}$ Les tendances catastrophistes de S. I. Witkiewicz se manifestent aussi bien dans son œuvre romanesque (L'Adieu à l'automne, 1927, L'Inassouvissement, 1930) que dans ses nombreuses pièces de théâtre avantgardistes. Szewcy [Les Cordonniers, 1931-1934], son dernier drame le plus proche des conventions théâtrales
} 
Aleksander Wat (1900-1967) ${ }^{26}$, vont s'intensifiant chez les poètes de la seconde avant-garde dans la deuxième décennie de cette période. Chez les premiers, elles résultent avant tout de l'expérience de la Première Guerre mondiale et de la Révolution russe, chez les seconds elles expriment l'angoisse devant une tragédie à venir.

Fondamentalement antiesthétiques, ces poètes hésitent entre le socialisme et la métaphysique. Pourtant, ils ont rejeté tout engagement politique qui pouvait menacer leur liberté poétique et ne composent des vers clairement antinazis que pendant l'occupation allemande. L’un des critiques littéraires caractérise ainsi leur écriture :

Un phénomène intellectuel et artistique de la poésie polonaise au cours de la seconde décennie de l'entre-deux-guerres, qui consistait à élaborer d'une manière symboliste [...] (avec parfois un soupçon de surréalisme ou d'expressionnisme) des thèmes qui suggéraient et annonçaient l'approche d'une inévitable catastrophe historique et morale ${ }^{27}$.

Les peintres des sombres visions dans lesquelles le politique se traduit en cosmique, publient principalement dans la revue qui porte un nom prémonitoire Żagary. Celui-ci signifie en lituanien des brindilles sèches à demi carbonisées par le feu, mais toujours rougeoyantes. Fondée en 1931 à Wilno par un groupe d'étudiants, dont Czesław Miłosz (1911-2004) et Jerzy Zagórski (1907-1984), la revue reflète les sentiments et les préoccupations de cette jeune génération d'écrivains.

Cependant, la meilleure illustration de ce courant «catastrophiste » est un poème «Żal » [Regret] écrit en 1939 par Józef Czechowicz (1903-1939), poète de Lublin, dont nous allons citer un fragment.

\footnotetext{
traditionnelles et le plus politique, constitue une parodie grotesque de trois régimes politiques, successivement la démocratie, appelée "démocratie insipide », le régime qu'il considère comme le plus menteur, parce qu'il n'est pas vrai que c'est le peuple qui gouverne ; le totalitarisme fasciste, qui est la négation même de la justice et de la dignité humaine, et enfin le communisme, qui nivellera l'humanité et supprimera définitivement l'individu.

${ }^{26}$ Dans son recueil de nouvelles satiriques teintées de grotesque Bezrobotny Lucyfer [Lucifer au chômage 1927], Aleksander Wat esquisse une philosophie de l'histoire très pessimiste : d'après une vielle conception cyclique, l'histoire du monde qui surgit après chaque nouvelle catastrophe doit en quelque sorte reproduire celle d'avant la catastrophe. Entre 1929 et 1931, Wat a rédigé Miesięcznik Literacki [Mensuel littéraire]. En 1931, avec Władysław Broniewski et d'autres collaborateurs communistes de ce mensuel, il a été arrêté par la sanacja et a passé trois mois en prison. Pendant la guerre, il a échappé aux nazis et s'est réfugié à Lwów, sous l'occupation soviétique. On l'a accusé tout de suite d'être à la fois trotskiste et sioniste, jeté en prison puis envoyé au Kazakhstan. Ce n'est qu'en 1946 qu'il a quitté l'Asie soviétique pour rentrer en Pologne. Voir aussi à ce propos Stanisław Fiszer, Le catastrophisme grotesque. La prose polonaise et l'anti-utopie européenne de l'entre-deuxguerres, op. cit.

${ }^{27}$ Cité d'après Czesław Miłosz, Histoire de la littérature polonaise, Fayard, 1986, p. 548.
} 
La vision d'une conflagration universelle y est intimement liée à l'obsession de sa propre mort $^{28}$. Dans la première strophe, le poète «porte [sa] tête » comparée à une torche au fond des ruelles d'une ville apparemment détruite. Le cri des hirondelles : «C'est peu. Va donc », traduit l'appel du destin qui le pousse à se soumettre à son sort. Puis il s'incarne dans les victimes d'un proche holocauste préfiguré, dès le début du poème, par l'image des « synagogues aux vitres brisées » :

\author{
Tombe le soir de ce monde \\ les narines hument le lait \\ rouge le déluge brûlant \\ nous nous accosterons en criant qui va là
}

\author{
Miraculeusement multiplié en tous \\ je tirerai sur moi et mourrai innombrable \\ moi collé au sillon avec le soc \\ moi juriste sur ses liasses \\ étranglé par le cri : gaz \\ moi dormeuse au sein des renoncules \\ moi enfant devenu torche vive \\ moi frappé d'une bombe dans l'église \\ moi incendiaire pendu \\ moi croix noire en bas d'une lettre
}

O moissons

moissons de fracas et de brasiers ${ }^{29}$.

\title{
De l'Anschluss aux Accords de Munich et ses suites
}

Alors que les catastrophistes n'ont réagi aux événements de l'année 1938-1939 que d'une manière implicite, il en est tout autrement pour les écrivains libéraux progressistes qui s'opposent de plus en plus ouvertement à la sanacja. Celle-ci approuve tacitement

\footnotetext{
${ }^{28}$ L'obsession de la mort se reflète dans toute l'œuvre poétique de Józef Czechowicz. Sa propre mort ressemble à un suicide car, selon les témoignages, étant chez le coiffeur lors d'un bombardement de Lublin le 9 septembre 1939, il s'est jeté vers la déflagration, alors que les autres clients s'en sont sortis indemnes.

${ }^{29}$ Józef Czechowicz, «Le regret », trad. en français par Constantin Jelenski, in idem, Anthologie de la poésie polonaise, L'Âge d'Homme, 1981, p. 309.
} 
l'Anschluss de l'Autriche (17 mars 1938), événement largement commenté par la presse polonaise.

Voici les titres de quelques articles parus dans le très libéral Ilustrowany Kurier Codzienny [Journal Quotidien Illustré] : «L'armée allemande est entrée en Autriche » ${ }^{30}$, «L'Anschluss sonne le glas de l'Autriche ${ }^{31}$, «La croix gammée au-dessus de Vienne ${ }^{32}$, «Vienne en uniforme brune $»^{33}$, «Les Juifs quittent 1'Autriche et s'exilent en Pologne ${ }^{34}$, «Londres ulcérée, mais impuissante ${ }^{35}$, «La carte de l'Europe de nouveau aux contours flous $»^{36}$. L'auteur d'un article $«$ Le doctrinarisme aveuglé des socialistes a ouvert la porte de Vienne à Hitler ${ }^{37}$ est quant à lui persuadé que la vacance gouvernementale en France provoquée par les socialistes qui avaient renversé le gouvernement Chautemps, a précipité l'Anschluss. Parmi les écrivains, les uns, comme Słonimski, affirment que de très nombreux Autrichiens sont saisis d'effroi, les autres, comme Witold Gombrowicz, témoin oculaire des événements, a beau chercher les signes de désespoir de la population autrichienne, ils ne les trouvent pas.

À peine quelques jours après l'Anschluss, le gouvernement polonais, soutenu par la presse nationaliste hystérique, lance un ultimatum aux Lituaniens : s'ils n'ouvraient pas immédiatement des relations diplomatiques avec Varsovie, rompues après l'annexion de Wilno par la Pologne en 1920, ils seront envahis. Profitant des accords de Munich, le $1^{\text {er }}$ octobre 1938, à la veille de l'occupation allemande des Sudètes, Varsovie adresse un autre ultimatum, cette fois-ci à Prague. La Tchécoslovaquie, sans coup férir, céda à la Pologne la région silésienne de Teschen, contestée depuis 1919. Alors que l'annexion de ce territoire très industrialisé et peuplé par une minorité polonaise importante suscite, d'après les historiens, l'enthousiasme d'une partie de l'opinion publique en Pologne $^{38}$, quelques journaux socialistes, tels que Robotnik [Ouvrier] et Czarno na Białem [Noir sur Blanc] dénoncent la politique pronazie du régime des colonels. En effet, elle a détérioré encore davantage l'image de la Pologne, considérée comme une « hyène » par les mêmes qui ont applaudi en Europe au « succès » des accords de Munich.

\footnotetext{
${ }^{30}$ Ilustrowany Kurier Codzienny (IKC), $\mathrm{n}^{\circ} 72,1938$.

${ }^{31} I K C, \mathrm{n}^{\circ} 73,1938$.

${ }^{32} I K C, \mathrm{n}^{\circ} 76,1938$.

${ }^{33} I K C, \mathrm{n}^{\circ} 79,1938$.

${ }^{34} I K C, \mathrm{n}^{\circ} 73,1938$.

${ }^{35} I K C, \mathrm{n}^{\circ} 73,1938$.

${ }^{36} I K C, \mathrm{n}^{\circ} 78,1938$.

${ }^{37} I K C, \mathrm{n}^{\circ} 73,1938$.

${ }^{38}$ Voir à ce propos les articles de Stanisław Żerko « Poland and Sudeten Crisis of 1938 » et de Jerzy Wojciech Borejsza «To the Question about Polish public Opinion concerning Munich Treaty (between the Third Reich and the USSR) », in Munich agreement of 1938 : History and Modernity, Moscou, 2009.
} 
Quant aux écrivains, ils sont partagés : leur dernier congrès avant la guerre, orchestré sans doute par le pouvoir et tenu à Cieszyn en mars 1939, acclame le « rattachement » de la Silésie de Teschen à la Pologne. Son annexion, ainsi que le démembrement progressif de la Tchécoslovaquie ont néanmoins provoqué l'indignation de quelques écrivains et intellectuels libéraux, comme Maria Dąbrowska ou Jerzy Stempowski. Ce dernier a constaté que l'annexion de la Silésie de Teschen était « un prélude à un nouveau partage de la Pologne » ${ }^{39}$. Dans ses Kroniki Tygodniowe, Słonimski compatit avec les Tchèques qui « sont tombés entre les pattes des sbires [...] de la Gestapo », mais en même temps il s'étonne que les Tchèques « ne se soient pas décidés à lutter pour leur liberté et pour la défense de leur honneur ${ }^{40}$, quelque « désespérée », concède-t-il, que cette lutte puisse paraître.

Quelques mois plus tard, la Pologne, en raison de sa politique erronée ${ }^{41}$ et des revendications allemandes intransigeantes, est à son tour menacée de disparition. Le 24 octobre 1938, Joachim von Ribbentrop présenta à Józef Lipski, l'ambassadeur de Pologne à Berlin, les revendications allemandes : la cession à l'Allemagne de la ville «libre» de Dantzig (Gdańsk), la construction d'une autoroute extraterritoriale entre le Reich et la Prusse orientale, l'accès de la Pologne au pacte anti-Kommintern. Finalement, ces revendications furent rejetées par les autorités polonaises au printemps 1939 et, le 5 mai, J. Beck, sous la pression de l'opinion publique, prononça au parlement un beau discours sur l'intransigeance et l'honneur polonais avant de partir pour Londres afin de s'assurer de l'aide anglaise en cas de guerre avec l'Allemagne.

Słonimski se réjouit alors de la rupture, le 24 avril 1939, du pacte de non-agression germano-polonais de 1934 et d'un rapprochement de son pays avec la Grande-Bretagne. Les dernières Chroniques hebdomadaires de cet auteur pacifiste devenu partisan d'une résistance

\footnotetext{
${ }^{39}$ Les propos cités par Maria Dąbrowska dans son Dziennik 1936-1945 [Journal 1936-1945], Warszawa, 2000, p. 219. L'écrivaine considère cette région comme historiquement polonaise, mais critique son annexion car elle a été faite de connivence avec l'Allemagne.

${ }^{40}$ Antoni Słonimski, Kroniki Tygodniowe, 1936-1939, Warszawa, 2004, p. 350.

${ }^{41}$ C'est le ministre des Affaires étrangères Józef Beck qui a mené une politique pro-allemande. C'est aussi lui qui est l'un des principaux instigateurs de l'annexion de la Silésie de Cieszyn. Léon Noël, ambassadeur de France à Varsovie de 1935 à 1939, caractérise ainsi les relations polono-tchécoslovaques de l'époque : «[...] l'aveuglement de Beck et de sa clique était incurable et il l'était d'autant plus que [...] "les animosités personnelles" jouaient un rôle capital dans cette affaire : "Le maréchal Piłsudski éprouvait pour le président Masaryk les sentiments que l'on connaît et celui-ci le lui rendait bien : le Maréchal a disparu, mais l'animosité que $\mathrm{M}$. Beck porte à $\mathrm{M}$. Benès égale celle qui animait le Maréchal à l'égard du président de la République tchécoslovaque, et je connais assez $\mathrm{M}$. Benès pour savoir que, de son côté, il ne nourrit pas une estime particulière pour son collègue polonais" », Léon Noël, La Pologne entre deux mondes, Publications de la Sorbonne, 1984, p. 209.
} 
armée à l'Allemagne nazie ${ }^{42}$, sont consacrées à la nécessité de purifier la vie publique des « restes d'une puanteur hitlérienne », tâche qui semblait d'autant plus facile que, les mois précédant la guerre, l'opinion polonaise était majoritairement antiallemande.

Ce qui au premier abord peut surprendre, c'est le silence, à de très rares exceptions près, des écrivains révolutionnaires face aux événements en question ${ }^{43}$. Pourtant, n'oublions pas que ces écrivains, sans être nécessairement membres du Parti communiste de Pologne, avaient adhéré, pour la plupart, à son idéologie. Or, le parti, même sous sa forme clandestine, n'existe plus en 1939. Ses dirigeants, victimes des «grandes purges » de 1937, ont été arrêtés et exécutés sur l'ordre de Staline, le parti a été officiellement dissous par le Komintern en 1938 sous l'accusation de trotskisme et d'infiltration par des agents de la sanacja ${ }^{44}$. Le dernier numéro de son organe de presse paraît en mai 1938, sa dernière déclaration date du 8 juin de cette même année. Décimés et désorientés, les communistes se taisent sans compter une voix. C'est celle de Władysław Broniewski dont le poème «Bagnet na broń !» [Baïonnette au canon !] était en 1939 sur toutes les lèvres. En voici un fragment :

\author{
Quand ils viendront incendier la maison, \\ celle qui est la tienne - la Pologne, \\ quand ils jetteront feu et flammes, \\ quand ils viendront, de nuit, \\ avec leur armée de fer et \\ donneront des coups de crosse dans ta porte, \\ toi, tiré du sommeil, le front haut, \\ dresse-toi à ta porte. \\ Baïonnette au canon! \\ Il faut du sang!
}

\footnotetext{
${ }^{42}$ Dans son poème Aux Allemands, écrit dès 1935, Słonimski appelle à une résistance armée à ceux-ci en faisant allusion au siège de Syracuse par une légion de Marcellus : «Archimède, défend-toi contre un soudard/ Archimède assassiné aujourd'hui ».

${ }^{43}$ Parmi ces exceptions, on peut citer Leon Kruczkowski dont la pièce Przygoda z Vaterlandem [Aventure avec Vaterland] devait être mise en scène à l'automne 1939. Cette pièce qui, d'une manière grotesque, montre la naissance et la montée du nazisme, est une réécriture de Bohater naszych czasów [Héros de nos jours], drame écrit et mis en scène en 1935. Dans les années 1936-1938, il publie encore des recueils d'articles : Dlaczego jestem socjalista [Pourquoi je suis socialiste] et $W$ klimacie dyktatury [Dans un climat de dictature].

${ }^{44}$ Certains historiens émettent l'hypothèse selon laquelle le Parti communiste de Pologne fut dissous en raison d'un rapprochement avec l'Allemagne hitlérienne envisagé par Staline dès la fin des années 30, le KPP pouvant constituer un sérieux obstacle à ce revirement politique. Pourtant, il est à remarquer qu'en avril 1939 Moscou engagea les pourparlers avec Londres et Paris, qui cherchaient à entraîner Varsovie dans une alliance antiallemande. Cette tentative se solda par un échec, la sanacja refusant catégoriquement de laisser, en cas de conflit, l'Armée rouge agir en territoire polonais.
} 
Dans ta patrie, il y a les comptes d'injustices à régler,

la main étrangère ne les effacera pas non plus,

mais personne ne refusera de donner son sang :

nous le ferons couler de nos poitrines et de nos chants.

Même si le pain avait parfois un goût amer

dans les geôles de ta patrie,

pour cette main levée sur la Pologne,

une balle dans la tête $!^{45}$

Quelque puissant que soit ce poème, il est loin de véhiculer l'internationalisme prêché par les écrivains révolutionnaires avant les purges staliniennes. En effet, toute sa vie durant, Broniewski est demeuré déchiré entre la cause révolutionnaire et son patriotisme ${ }^{46}$. Ce trait caractérise, d'ailleurs, d'autres écrivains de la gauche polonaise, qui, aux moments décisifs de l'histoire de leur pays, choisirent souvent la cause nationale au détriment des idéaux internationalistes. Le cas échéant, ces derniers ont toutefois été trahis par celui qui était censé les incarner et qui fera signer, fin août 1939, le pacte Ribbentrop-Molotov.

\section{Des itinéraires dramatiques}

Quelles conclusions pourrait-on tirer de cette étude qui ne prétend pas à l'exhaustivité ? Premièrement, les représentants de trois courants littéraires dont nous venons de parler se sont bien rendus compte du danger nazi, pratiquement dès l'arrivée d'Hitler au pouvoir; ils ne se sont intéressés qu'accessoirement au fascisme italien, l'Italie étant relativement loin de la Pologne et le régime de Mussolini étant jugé beaucoup moins oppressif et menaçant que celui du dictateur allemand.

Deuxièmement, aussi bien les écrivains révolutionnaires que les libéraux de gauche ont combattu à la fois les fascismes européens et les tendances fascisantes au sein de la sanacja et de l'extrême droite polonaise dont celle-ci s'était rapprochée après la mort de Józef Piłsudski. Toujours est-il qu'à la différence des écrivains communistes, les libéraux de gauche se méfiaient du régime stalinien et n'hésitaient même pas à établir certaines analogies entre celui-ci et le totalitarisme hitlérien.

\footnotetext{
45 Ryszard Matuszewski, Seweryn Pollak, Poezja polska 1914-1939. Antologia [Poésie polonaise 1914-1939. Anthologie], Warszawa, Czytelnik, 1966, p. 469. Traduction du poème par Stanisław Fiszer.

${ }^{46}$ Lors de la guerre polono-soviétique de 1920, Władysław Broniewski, encore proche de Józef Piłsudski, mais déjà imprégné d'idées socialistes, s'était enrôlé dans l'armée polonaise pour combattre les bolcheviques.
} 
Troisièmement, l'année qui précède la guerre, les prises de position de la gauche et de la droite littéraire ont commencé à converger dans la mesure où toutes les deux, malgré la divergence d'idées fondamentale qui les séparait, ont affirmé le devoir de s'opposer à l'Allemagne au nom de la défense de la patrie.

Pour terminer, il convient de rappeler ici que les hommes de lettres de gauche ont payé cher leur antifascisme : les uns, en tant que communistes, seront traqués en Pologne par la sanacja ou liquidés en Union soviétique par le régime stalinien dès avant la guerre ${ }^{47}$, les autres auront dû s'exiler après la débâcle en septembre $1939^{48}$, ou entrer dans la clandestinité sous l'occupation allemande du pays. Ceux qui auront survécu à la guerre et se seront résolu à vivre dans la Pologne communiste, auront été amenés à choisir entre le soutien apporté au nouveau régime et le refus de s'engager au risque d'être marginalisés ou réduits au silence. Plusieurs, en tout cas, auront choisi l'engagement. De ce fait, ils doivent maintenant faire leur purgatoire. Car après la mutation capitaliste de la Pologne en 1989, les gouvernements de droite successifs s'efforcent de reléguer au second plan, voire, en considération de la « décommunisation», d'effacer de la mémoire collective ces hommes auxquels nous espérons, grâce à cet article, contribuer à rendre vie.

\section{Bibliographie}

Dedecius Karl (dir.), Panorama de la littérature polonaise du XX $X^{e}$ siècle, Paris, Les Éditions Noir sur Blanc, 2000.

Fiszer Stanisław, Le Grotesque de l'Histoire (dir.), Paris, Le Manuscrit, 2005.

Fiszer Stanisław, Le catastrophisme grotesque. La prose polonaise et l'anti-utopie européenne de l'entre-deux-geurres, Paris, Le Manuscrit, 2007.

Jeleński Constantin, Anthologie de la poésie polonaise, L’Âge d’Homme, 1981.

\footnotetext{
${ }^{47}$ Bruno Jasieński sera l'une des victimes des «purges staliniennes ». En 1926, il avait composé Słowo o Jakubie Szeli [Le Dit de Jakub Szela], un long poème consacré au soulèvement de paysans en 1846-1848. En 1925, il avait émigré, en France. En 1929, L'Humanité avait publié Je brûle Paris, roman qui montre d'une manière grotesque les contradictions insolubles du capitalisme, lesquelles entraînent l'instauration d'une dictature. La même année, il avait été expulsé hors de France pour son activisme communiste. Exilé à Moscou, il avait écrit son premier roman du réalisme socialiste L'homme change de peau (1932) et était devenu membre du comité exécutif de l'Union des écrivains soviétiques. Arrêté par le régime stalinien, en 1937, il sera fusillé en 1938.

${ }^{48}$ Parmi les hommes de lettres dont nous venons de parler et qui auront dû quitter le pays, on peut mentionner Julian Tuwim (il vivra en exil à Rio de Janeiro et à New York) et Antoni Słonimski (il se rendra en France, puis en Angleterre). Quant à Władysław Broniewski, il partira en septembre 1939 à Lwów, qui tombera peu après aux mains de l'Union soviétique en vertu du pacte Ribbentrop-Molotov. Traité d'abord avec égards, il sera arrêté au début de 1941 et incarcéré à Moscou. Libéré après l'invasion de l'URSS par l'Allemagne, il s'enrôlera dans l'armée du général Anders et partira avec elle pour l'Iran, l'Irak et la Palestine. Après la guerre, ces trois écrivains en question retourneront en Pologne pour apporter leur soutien plus ou moins actif au nouveau régime.
} 
Kwiatkowski Jerzy, Literatura dwudziestolecia [La littérature de la Pologne indépendante 1918-1939], Warszawa, Państwowe Wydawnictwo Naukowe, 1990.

Lebedeva N. S., Wołos M. (dir.), Munich Agreement of 1938: History and Modernity, Moscow, 2009.

Matuszewski Ryszard, Pollak Seweryn, Poezja polska 1914-1939. Antologia [Poésie polonaise 1914-1939. Anthologie], Warszawa, Czytelnik, 1966.

Miłosz Czesław, Histoire de la littératue polonaise, Paris, Fayard, 1986.

Sandauer Artur, Poeci trzech pokoleń [Les poètes de trois générations], Kraków, Wydawnictwo Literackie, 1977.

Słonimski Antoni, Kroniki tygodniowe 1927-1931 [Chroniques hebdomadaires 1927-1931], Warszawa, Wydawnictwo LTW, 2001.

Słonimski Antoni, Kroniki tygodniowe 1932-1935 [Chroniques hebdomadaires 1932-1935], Wydawnictwo LTW, Warszawa, 2001.

Słonimski Antoni, Kroniki tygodniowe 1936-1939 [Chroniques hebdomadaires 1936-1939], Warszawa, Wydawnictwo LTW, 2004.

Słonimski Antoni, Dwa końce świata [Deux fins du monde], Warszawa, Książka i Wiedza, 1991.

Sobczak Paweł Maurycy, Polscy pisarze wobec faszyzmu [Les écrivains polonais face au fascisme], Łódź, Wydawnictwo Uniwersytetu Łódzkiego, 2015.

Stępień Marian, Antologia polskiej poezji rewolucyjnej 1918-1939 [Anthologie de la poésie révolutionnaire polonaise 1918-1939], Wrocław, Zakład Narodowy imienia Ossolińskich, 1982. 
